\title{
O USO DO QR CODE COMO FERRAMENTA PARA O ENSINO DE BOTÂNICA EM ESPAÇO NÃO FORMAL DE EDUCAÇÃO
}

\author{
THE USE OF QRCODE AS A TOOL FOR BOTANICAL EDUCATION \\ IN NON-FORMAL EDUCATION AREA
}

\author{
DINARDI, Ailton Jesus ${ }^{1}$ \\ OLIVEIRA, Márcio Jonas Dornelles ${ }^{2}$ \\ MEDINA, Carla Cristina Borges ${ }^{3}$ \\ CASTRO, Luis Roberval Bortoluzzi ${ }^{4}$
}

\begin{abstract}
RESUMO
Em pleno século XXI, ainda nos deparamos com métodos de ensino centralizados somente no saber do professor e na condição de alunos passivos, em uma educação dita como bancária. Como forma de superação e ressignificação do ensino, o uso de tecnologias e de espaços urbanos podem ser condições importantes para a superação desse modelo tradicional. O presente estudo objetivou contribuir para com o ensino de Botânica. Em 2017, elaborou-se uma trilha ecológica na Praça Dom Pedro II (Parcão), no município de Uruguaiana, e utilizou-se o $Q R$ Code para identificar vinte e cinco espécies de árvores. Ao se acessar o link do código, cada espécie estava descrita com suas características morfológicas e fenotípicas. Nesse sentido, aliaram-se ao ensino da botânica instrumentos tecnológicos atuais, que estão disponíveis aos estudantes da educação básica, possibilitando uma nova forma de ensino e aprendizagem em Botânica. Os resultados obtidos com as atividades demonstram que a praça ainda é pouco explorada como espaço social e educacional, que os alunos conhecem pouco da flora urbana e que a atividade com o uso do $Q R$ Code provocou interesse, porém o processo poderia ser melhor aproveitado se o sinal público de internet chegasse com maior intensidade ao local.
\end{abstract}

PalaVRas-chave: Tecnologias na educação; Educação ambiental; Ensino de ciências.

\begin{abstract}
In the 21st century we are still faced with teaching methods centered only on the teacher's knowledge and the condition of passive students in an education called banking. As a way of

1 Universidade Federal do Pampa - UNIPAMPA. Uruguaiana, RS, Brasil. ORCID: https://orcid.org/0000-00025625-1787 e-mail: ailtondinardi@gmail.com

2 Universidade Federal do Pampa - UNIPAMPA. Uruguaiana, RS, Brasil. e-mail: marcio_jonas@hotmail.com 3 Universidade Federal do Pampa - UNIPAMPA. Uruguaiana, RS, Brasil. e-mail: carlab_m@hotmail.com 4 Universidade Federal do Pampa - UNIPAMPA. Uruguaiana, RS, Brasil. ORCID: https://orcid.org/0000-00026272-5854 e-mail: Ibortoluzzi@gmail.com
\end{abstract}


DOI: $10.12957 / \mathrm{e}-\mathrm{mosaicos} .2021 .46188$

overcoming and reframing education, the use of technologies and urban spaces may be important conditions for overcoming this traditional model. This study aimed to contribute to the teaching of Botany. In 2017 an ecological trail was elaborated in Dom Pedro II Square (Parcão) in the municipality of Uruguaiana and the QR Code was used to identify 25 tree species by accessing the code each species was described with its morphological and phenotypic characteristics. In this sense, it was combined the teaching of botany with current technological tools that are available to students, with it was offered to students of basic education a new possibility of teaching and learning of botany. The results obtained from the activities show that the square is still little explored as a social and educational space, that the students know little about urban flora and that the activity using the QR Code provoked interest, but the process could be better used if the public internet signal would arrive more intensely at the site.

KeYwORDS: Technologies in Education; Environmental Education; Science Teaching.

\section{INTRODUÇÃo}

Em meio a tantas novidades tecnológicas que o mercado apresenta diuturnamente às nossas crianças e a nossos adolescentes, colocando-os em contato com a informação quase que em tempo real, ainda nos deparamos com escolas cuja metodologia de ensino está centrada no modelo dito "tradicional", no qual o professor é visto como o detentor do saber e os alunos como tábulas rasas, sujeitos passivos no processo de ensino e de aprendizagem.

Para Castoldi e Polinarski (2009), muitos professores adotam métodos tradicionais de ensino por medo de inovar ou mesmo pela inércia há muito estabelecida em nosso sistema educacional.

Santana (2015, p. 11) ressalta que "[...] um dos principais desafios do professor é planejar aulas estimulantes e motivadoras. Nesse sentido, a utilização de diferentes recursos didáticos propiciará ao aluno a melhor compreensão dos conteúdos". Já Pessano et al. (2015) apostam, na contextualização como forma de aproximação dos alunos aos conteúdos e de melhoria dos resultados escolares, porém, para que isso ocorra, 0 empenho da escola e de seus professores é necessário.

Para Serafim (2001), a teoria é feita de conceitos, os quais são abstrações da realidade, inferindo-se que o aluno que não reconhece o conhecimento científico em situações do seu cotidiano não foi capaz de compreender a teoria. Corrobora com essa afirmação, Santana (2015), ao registrar que no ensino de Ciências pode-se destacar a dificuldade que o aluno apresenta em relacionar a teoria desenvolvida em sala de aula com a realidade à sua volta.

Para Nicola e Paniz (2016, p. 358), Ciências e Biologia são disciplinas que muitas vezes não despertam o interesse dos alunos devido 
DOI: $10.12957 / \mathrm{e}-\mathrm{mosaicos} .2021 .46188$

[...] À utilização de nomenclaturas complexas dos seus conteúdos. Isso exige que o professor faça a transposição didática de forma adequada e também que use de diversas estratégias e recursos. A utilização de jogos; de filmes; de oficinas orientadas; de aulas em laboratório; de saídas de campo, são alguns recursos que podem ser utilizados a fim de possibilitar a compreensão dos alunos no sentido da construção de conhecimentos relacionados à área.

E Krasilchik (2008, p. 11) afirma que

[...] a Biologia pode ser uma das disciplinas mais relevantes e merecedoras da atenção dos alunos ou uma das disciplinas mais insignificantes e pouco atraentes, dependendo do que for ensinado e de como isso for feito.

Mais especificamente, com relação à Botânica, Araújo e Miguel (2013) descrevem que o ensino se apresenta voltado para a exposição didática dos conteúdos, o que vem a desmotivar e dificultar o aprendizado dos alunos. Normalmente, para o ensino desses conteúdos não são utilizados procedimentos que permitam o contato dos alunos com os vegetais, o que tornam maiores as dificuldades de ensinar $e$, consequentemente, de aprender Botânica.

Embora a Botânica esteja inserida como conteúdo do 70 ano do ensino fundamental e do $2^{\circ}$ ano do ensino médio, a abordagem dos assuntos relacionados a esse componente torna-se um desafio constante para os professores de Ciências da Natureza e Biologia, visto que há dificuldade em transpor didaticamente os conhecimentos específicos em uma linguagem plausível para a educação básica. Diante dessas dificuldades, muitas vezes, o professor opta e prioriza as modalidades convencionais de comunicação.

Em meio a essa série de fatores que impactam o ensino de modo geral e o ensino de Botânica, mais especificamente, pode-se inferir que o uso de tecnologias e de espaços urbanos, ditos não formais, podem contribuir no processo de ensino e de aprendizagem em ciências, na educação básica.

Com o objetivo de contribuir para com o ensino e a aprendizagem dessa disciplina, foi implantado, em 2017, um projeto de extensão com uma trilha "ecológica" na Praça Dom Pedro II (Parcão), no município de Uruguaiana, que utilizou o uso do $Q R$ Code para apresentar as características morfológicas e fenotípicas das árvores demarcadas na trilha.

Segundo Oliveira, (2013, p. 15), "[...] o uso de TICs (Tecnologia da Informação e Comunicação) traz às escolas uma reestruturação do currículo e novas definições 
DOI: $10.12957 / \mathrm{e}-\mathrm{mosaicos} .2021 .46188$

pedagógicas do ensino, e, se utilizadas adequadamente, podem ser um grande potencial de transformação da educação".

Para Nichele, Schlemmer e Ramos (2015), a crescente adoção de dispositivos móveis, como smartphones e tablets, pelos estudantes é um fenômeno que desafia as instituições de ensino a incorporá-los no contexto educacional. A partir dessa realidade, uma das possibilidades que emergem é a de estimular estudantes e professores a trazerem seus próprios dispositivos móveis para as atividades educacionais.

Segundo Frantz et aı. (2016), o uso do celular, proibido na maioria das escolas, foi ressignificado como recurso pedagógico por meio do $Q R$ Code, que é uma ferramenta válida de aprendizagem.

O QR Code, sigla em inglês para "resposta rápida", é um código de barras 2D criado por volta de 1994, por uma empresa japonesa, com intuito de identificar peças na indústria automobilística. Desde 2003, é usado para ver, ler e ouvir dados pelos telefones através da leitura feita pela câmera dos dispositivos. Trata-se de um código que pode ser escaneado pela maioria dos aparelhos celulares, desde que tenham câmera, um software adequado e internet para a leitura (SILVA; BEZERRA, 2016).

Ao optar pelo uso dos $Q R$ Codes, o projeto vai ao encontro do que diz a Base Nacional Comum Curricular (BNCC), que registra

[...] dentre as competências específicas de linguagens para o ensino fundamental encontra-se, compreender e utilizar tecnologias digitais de informação e comunicação de forma crítica, significativa, reflexiva e ética nas diversas práticas sociais (incluindo as escolares), para se comunicar por meio das diferentes linguagens e mídias, produzir conhecimentos, resolver problemas e desenvolver projetos autorais e coletivos (BRASIL, 2017, p. 63).

Para Nichele, Schlemmer e Ramos (2015, p.3),"[...] a criação de $Q R$ Codes pode ser uma interessante estratégia de ensino e de aprendizagem, cujos objetivos são a produção e a socialização de materiais, o desenvolvimento da autoria, da autonomia e do trabalho colaborativo".

Klix diz que (2018), criar um $Q R$ Code não exige conhecimentos de programação ou design. Com um aplicativo em seu celular, escolha que tipo de informação o $Q R$ Code vai armazenar (link de internet, texto, número de telefone, post no Facebook, arquivo PDF), indique o conteúdo em um campo específico e gere o código. Depois, é possível salvar o código como imagem e usar da maneira mais adequada para cada situação. 
DOI: $10.12957 / \mathrm{e}-\mathrm{mosaicos} .2021 .46188$

Algumas funcionalidades como usar cor no código ou ter acesso a estatísticas sobre seu uso são cobradas.

Segundo Silva e Bezerra (2016, p.11)

[...] embora ainda seja uma dificuldade para os professores utilizarem esse tipo de tecnologia em sala, por que existem gestões em escolas que proíbem o uso de celulares durante as aulas, acreditamos que o uso desses aparelhos, nesse caso, seria de benefício para ambas as partes, pois se trata de utilizar o celular como um recurso didático inovador para o ensino e para o aprendizado dos alunos.

Para Guimarães (2015), as TICs funcionam como instrumentos que interferem na maneira de pensar, aprender, conhecer, representar e, portanto, de construir conhecimentos, fazendo-se necessário identificar, entender e avaliar o impacto que essas transformações tecnológicas produzem no ambiente educacional.

\section{Procedimentos metodológicos}

A presente pesquisa foi desenvolvida no ano de 2017, no município de Uruguaiana, Estado do Rio Grande do Sul, sendo dividida em duas fases: a implantação da trilha ecológica na Praça Dom Pedro II (Parcão) com a geração dos QR Codes para as espécies arbóreas e o processo de ensino e de aprendizagem utilizando-se desse espaço.

\section{IMPLANTAÇÃO DA TRILHA ECOLÓGICA E GERAÇÃo dOS QR CODES}

Em Uruguaiana são encontradas inúmeras praças públicas, mas especificamente na Praça Dom Pedro II, mais conhecida como Praça do Parcão que se localiza na região central da cidade. Pode-se dizer que há grande variedade de espaços com vocação para 0 ensino e a aprendizagem de ciências em espaço não formal. Na praça, encontram-se um relógio de sol, uma pista de skate, uma pista de caminhada, uma ciclovia e grande diversidade de árvores e arbustos nativos e exóticos (DINARDI; FEIFFER; FELIPPELLI, 2018).

Em um primeiro momento, houve a identificação das espécies arbóreas com auxílio dos guias de identificação de Backes e Irgang (2002), Backes e Irgang (2004) Sobral et al (2006). Após a identificação, realizou-se uma pesquisa sobre suas características morfofisiológicas, origem e fenologia, elaborando-se textos com uma linguagem didática e que atraísse a atenção dos visitantes. 
DOI: $10.12957 / \mathrm{e}-\mathrm{mosaicos} .2021 .46188$

Também foi realizada a gravação de áudio com as apresentações das espécies, seguido da criação de um canal no YouTube denominado BOTÂNICACN2017, para postagem e armazenamento dos áudios com um conjunto de imagens referente à cada espécie e à criação dos códigos $Q R$ para cada exemplar.

Próximo ao tronco das espécies selecionadas, fixou-se uma placa de identificação com o nome comum, nome científico, família botânica e características gerais, bem como uma numeração sequencial que permite aos visitantes percorrer de forma pré-estabelecida todo o percurso da trilha (Fig.1).

Figura 1 - Modelo de placa de identificação usada na demarcação das espécies na Praça do Parcão (Dom Pedro II)

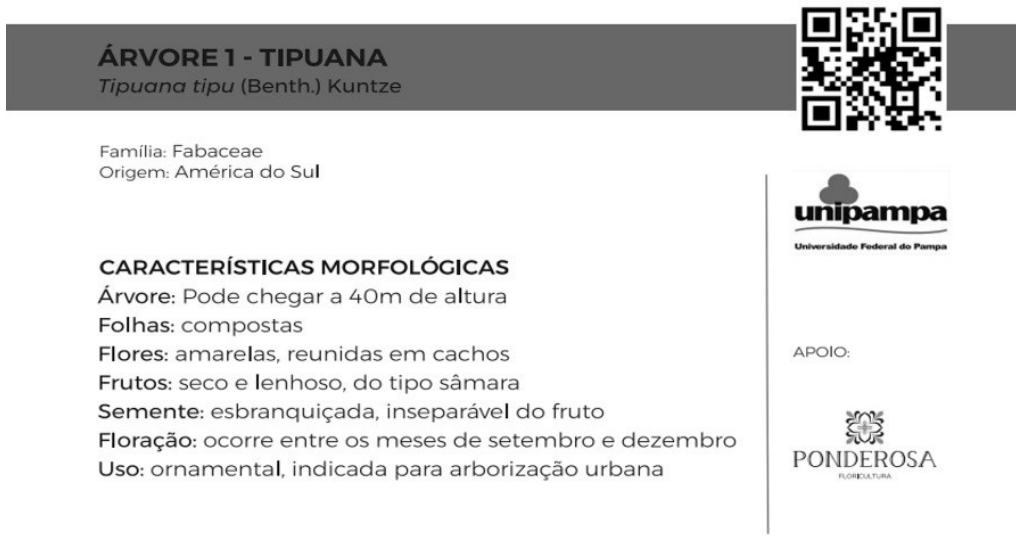

Fonte: Elaborado pelos autores

Nesse sentido, ao acessar o $Q R$ Code, via celular, o sistema encaminha o visitante à página, na qual o usuário poderá ouvir as explicações e visualizar as imagens das espécies ao longo de sua caminhada.

\section{Metodologia das atividades de Ensino e Aprendizagem de Botânica com o uso dos QR CODES}

As atividades na praça ocorreram mensalmente, sendo ofertadas aos alunos do ensino fundamental II ( $6^{\circ}$ ao $9^{\circ}$ ano) das escolas públicas e particulares de Uruguaiana, que foram acompanhadas por estudantes bolsistas e voluntários do Curso de Ciências da Natureza da UNIPAMPA, Campus Uruguaiana. Nesse estudo, utilizaram-se os dados referentes às respostas de 55 alunos (as) do ensino fundamental, sendo a Escola 1 (Particular- 40 alunos) e a Escola 2 (Pública - Estadual - 15 alunos). 
DOI: $10.12957 / \mathrm{e}-\mathrm{mosaicos} .2021 .46188$

Os alunos das escolas envolvidas foram recebidos na praça em uma roda de conversa onde se dialogou sobre o Parcão, a história cultural dos personagens que nomeiam as ruas do entorno e, principalmente, sobre as árvores presentes no ambiente, suas funções, características e peculiaridades a fim de buscar informações sobre os conhecimentos prévios dos pesquisados.

Com o uso de smartfone com acesso à internet e com caixa de som, os monitores do projeto, durante a trilha, foram falando sobre as espécies de árvores, apresentando os $Q R$ codes e suas informações, e, dependendo do grau de interesse, as informações eram enriquecidas e complementadas.

Como forma de contribuir com o processo de ensino e de aprendizagem, foram criados jogos do tipo quebra-cabeças (Fig.2) com imagens das espécies visitadas. Ao final da trilha, os alunos eram convidados a montar o quebra-cabeças. Eles eram direcionados até o exemplar, e novamente a espécie era descrita de acordo com suas características, a fim de reforçar as informações dos interessados que estavam novamente no local, com objetivo de montar o jogo.

Figura 2 - Modelo de Jogo do tipo Quebra cabeças com a imagem da espécie Tipuana

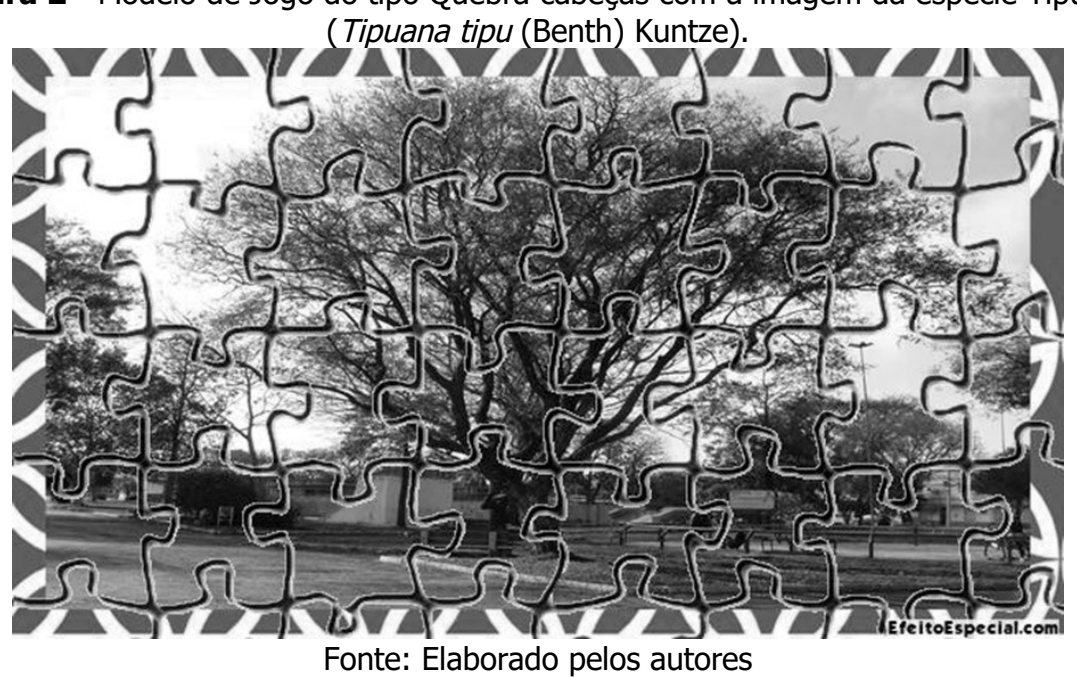

Após uma semana das visitas, os alunos responderam a um questionário em sala de aula, que objetivou analisar os conhecimentos adquiridos e onde os alunos poderiam descrever e registrar os pontos positivos e negativos do projeto. As respostas dos alunos foram analisadas e categorizadas seguindo Bardin (2011) e separadas por escola. 
DOI: $10.12957 / \mathrm{e}-\mathrm{mosaicos} .2021 .46188$

\section{RESULTADOS E DISCUSSÃo}

\section{IDENTIFICAÇÃO DAS ESPÉCIES ARBÓREAS E DEMARCAÇÃO DA TRILHA ECOLÓGICA}

Na praça, existem várias espécies de árvores, nativas e exóticas; algumas se repetem ao longo do percurso. A fim de criar um percurso para a trilha, para que o visitante pudesse caminhar por toda a praça, foram demarcados os exemplares que estivessem localizados próximos à pista de caminhada e a uma certa distância um do outro (Quad.1).

Quadro 1. Espécies selecionadas para compor a trilha na Praça Dom Pedro II (Parcão).

\begin{tabular}{|c|l|l|l|l|}
\hline No & \multicolumn{1}{|c|}{ Família } & \multicolumn{1}{|c|}{ Espécie } & \multicolumn{1}{c|}{ N. Vulgar } & \multicolumn{1}{c|}{ Origem } \\
\hline 1 & Fabaceae & Tipuana tipu (Benth.) Kuntze & Tipuana & América do Sul \\
\hline 2 & Bignoniaceae & $\begin{array}{l}\text { Handroanthusheptaphyllus } \\
\text { (Mart.) Mattos }\end{array}$ & Ipê Rosa & América do Sul \\
\hline 3 & Myrtaceae & Eugenia uniflora L. & Pitanga & Brasil \\
\hline 4 & Taxodiaceae & Taxodiummucronatum Ten. & $\begin{array}{l}\text { Cipreste } \\
\text { Calvo }\end{array}$ & México e EUA \\
\hline 5 & Meliaceae & CedrelafissilisVell. & Cedro Rosa & Brasil \\
\hline 6 & Casuarinaceae & Casuarina equisetifolia L. & Casuarina & Austrália, Oceania \\
\hline 7 & Fabaceae & $\begin{array}{l}\text { Enterolobiumcontortisiliquum } \\
\text { (Vell.) Morong }\end{array}$ & Tamboril & Brasil \\
\hline 8 & Bignoniaceae & Tabebuia pentaphyllaHemsl. & $\begin{array}{l}\text { Ipê de El } \\
\text { Salvador }\end{array}$ & El Salvador \\
\hline 9 & Bignoniaceae & Jacarandamimosaefolia D. Don. & $\begin{array}{l}\text { Jacarandá } \\
\text { Mimoso }\end{array}$ & América do Sul \\
\hline 10 & Boraginaceae & Patagonula americana L. & Guajuvira & América do Sul \\
\hline 11 & Fabaceae & $\begin{array}{l}\text { Peltophorumdubium (Sprengel) } \\
\text { Taubert }\end{array}$ & Canafístula & América do Sul \\
\hline 12 & Anacardiaceae & SchinusterebinthifoliusRaddi & $\begin{array}{l}\text { Aroeira } \\
\text { Pimenteira }\end{array}$ & América do Sul \\
\hline 13 & Myrtaceae & Psidiumcattleyanum & Araçá & América do Sul, Brasil \\
\hline 14 & Bignoniaceae & $\begin{array}{l}\text { Handroanthusalbus (Chamiso) } \\
\text { Mattos }\end{array}$ & Ipê Amarelo & Brasil \\
\hline 15 & Fabaceae & Erythrinacristagalli L. & Corticeira & América do Sul \\
\hline 16 & Moraceae & Ficusbenjamina & Ficus & Ásia \\
\hline
\end{tabular}


DOI: $10.12957 / \mathrm{e}-\mathrm{mosaicos} .2021 .46188$

Quadro 1. Espécies selecionadas para compor a trilha na Praça Dom Pedro II (Parcão).

\begin{tabular}{|c|c|c|c|c|}
\hline No & Família & Espécie & N. Vulgar & Origem \\
\hline 17 & Platanaceae & Platanusacerifolia & Plátano & $\begin{array}{l}\text { Europa e América do } \\
\text { Norte }\end{array}$ \\
\hline 18 & Salicaceae & Salix $x$ pendulina & $\begin{array}{l}\text { Salgueiro } \\
\text { Chorão }\end{array}$ & Ásia e China \\
\hline 19 & Fabaceae & $\begin{array}{l}\text { Schizolobiumparahyba (Vellozo) } \\
\text { S. F. Blake }\end{array}$ & Guapuruvu & Brasil \\
\hline 20 & Salicaceae & Populusnigra & Álamo & África, Ásia e Europa \\
\hline 21 & Proteaceae & Grevillea robusta A. Cunn & Grevilha & Austrália \\
\hline 22 & Fabaceae & $\begin{array}{l}\text { Caesalpinia pluviosa DC. var. } \\
\text { peltophoroides (Benth.) }\end{array}$ & Sibipiruna & Brasil \\
\hline 23 & Rhamnaceae & Hoveniadulcis & Uva do Japão & Ásia \\
\hline 24 & Malvaceae & $\begin{array}{l}\text { Ceiba speciosa (St. Hill.) } \\
\text { Ravenna }\end{array}$ & Paineira & Brasil \\
\hline 25 & Apocynaceae & Neriumoleander & Espirradeira & Norte da África \\
\hline
\end{tabular}

Fonte: Elaborado pelos autores

Os exemplares foram selecionados com o objetivo de proporcionar aos visitantes a condição de caminhada por toda a praça, porém, mantendo-se certa distância um do outro (Fig.3).

Figura 3 - Posição das espécies selecionadas ao longo da pista de caminhada na Praça Dom Pedro II (Parcão).

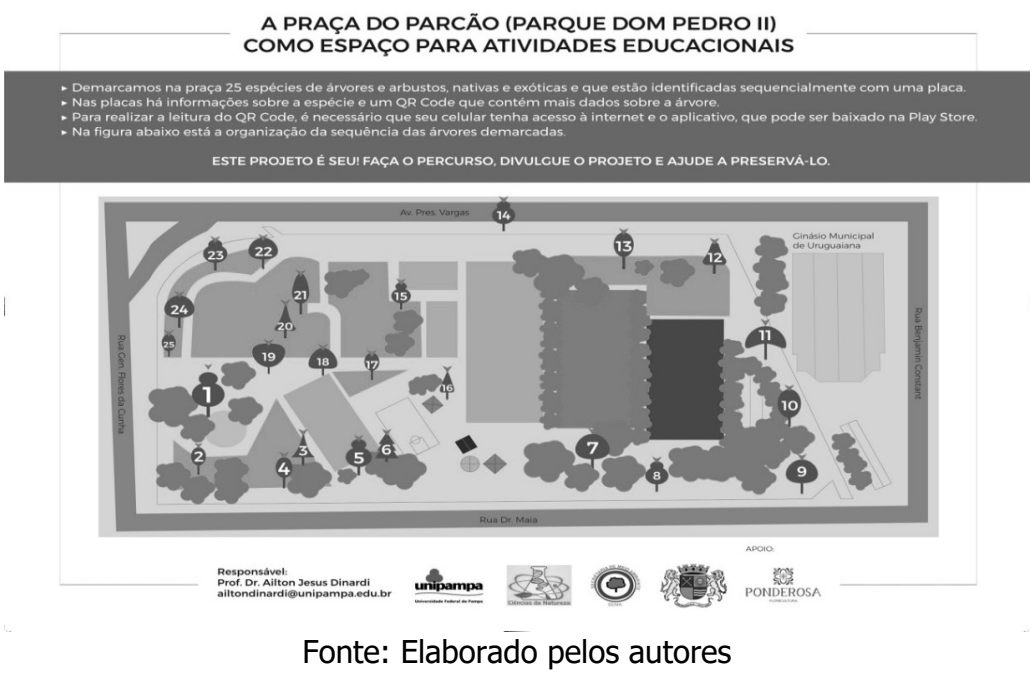


DOI: $10.12957 / \mathrm{e}-\mathrm{mosaicos} .2021 .46188$

\section{Atividades de Ensino e Aprendizagem de BotÂnica com o uso de QR CODE}

Para Carvalho (1998), o passeio pelo bairro e pela escola pode ser um ótimo exercício para aprender a olhar com novos olhos aquilo que se vê diariamente. MoreiraConeglian, Diniz e Bicudo (2004) relatam que as praças e jardins públicos, além de possuírem componentes vegetais e animais, podem contar a história da cidade, visto que apresentam em seus arredores todo um patrimônio histórico e cultural. Em consonância, Dinardi (2005) ressalta ser conveniente que a escola participe de movimentos de defesa ao meio ambiente; possibilite a saída de alunos para passeios e para visitas a locais de interesse dos trabalhos em Educação Ambiental; mantenha contato com instituições, empresas, parques, unidades de conservação, serviços públicos, lugares históricos e centros culturais para o desenvolvimento de estudos.

Entretanto, em uma roda de conversa antes da caminhada, quando perguntado aos alunos sobre o uso da Praça Dom Pedro II (Parcão), 72,7\% dos alunos da Escola 1 e $88,9 \%$ da Escola 2 responderam que usam a praça raramente, ou seja, apesar de ser uma das mais importantes praças do município, os alunos não tinham o hábito de frequentar a praça.

Aumentar o uso das praças e parques da cidade vai ao encontro do PNE (20142024) que registra, na Estratégia 6.4 da Meta 6, que o atendimento ao que se propõe dependerá de diversas ações, dentre elas fomentar a articulação da escola com os diferentes espaços educativos, culturais e esportivos, com o uso de equipamentos públicos (BRASIL, 2014).

Os percentuais encontrados vão ao encontro dos valores obtidos por Dinardi, Feiffer e Felippelli (2018). Ao serem indagados, alunos e alunas de três turmas de $6^{\circ}$ ano de uma escola pública de Uruguaiana, sobre o uso da Praça Dom Pedro II (Parcão), obteve-se como resposta que, $56,3 \%$ das meninas e $76,2 \%$ dos meninos, raramente utilizam a Praça do Parcão, ou seja, pode-se inferir que, de forma voluntária ou de forma estimulada pelos professores e pelas escolas, a praça em questão é pouco visitada pelos estudantes da educação básica do município.

Quando perguntado aos alunos sobre a importância das plantas, a maioria dos alunos respondeu: "oxigênio", com 43,0\% e 52,0\% para as escolas 1 e 2, respectivamente (Fig.4). 
DOI: $10.12957 / \mathrm{e}-\mathrm{mosaicos} .2021 .46188$

Figura 4 - Importância atribuída às árvores pelos alunos das duas escolas (\%).

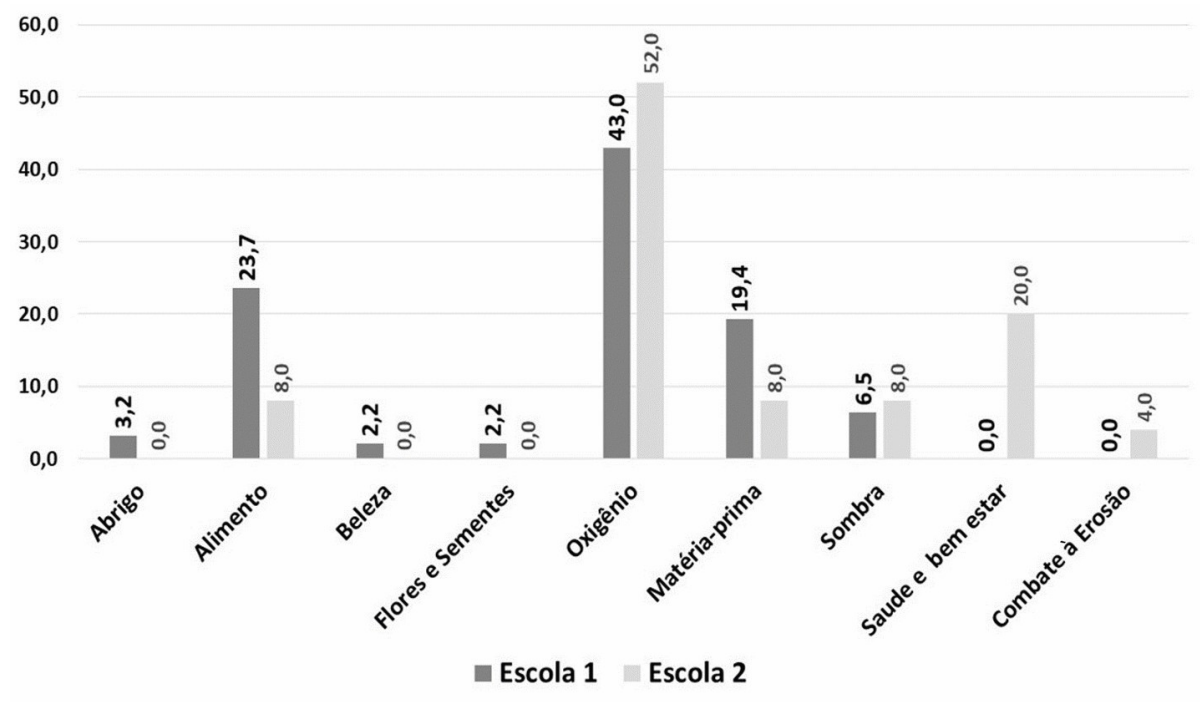

Fonte: Elaborado pelos autores

Esses resultados apontam que outros fatores vêm sendo relegados no processo de ensino e aprendizagem, principalmente a estética (beleza) e a importância da biodiversidade das plantas para a manutenção do equilíbrio ambiental.

Quando perguntado aos alunos de forma livre, ou seja, sem limites de quantidade, sobre as árvores que os alunos mais conheciam, as frutíferas aparecem com maior percentual nas duas escolas, com 50,4\% para a Escola 1 e 57,1\% para a Escola 2, sendo que, nessa relação prévia, as espécies presentes na praça não foram citadas por nenhum aluno das duas escolas.

Segundo Brasil (2009), as árvores são denominadas como vegetal superior lenhoso constituído de uma porção superior folhosa, denominada copa, de um tronco suporte livre de ramificações, denominado fuste, e de um sistema radicular- raiz que prende este conjunto ao solo. Alunos das duas escolas também citaram, como exemplos de árvores, espécies de plantas que não se caracterizam por este hábito de crescimento e que foram organizadas na Fig.5 como "Erro de Conceito". Dentre as espécies citadas nessa categoria, encontra-se a bananeira (Musa spp), a vitória-régia (Victoria amazonica (Poepp) Sowerby), o Porongo (Lagenaria vulgaris Ser), a mamoneira (Ricinus communis L.) e as samambaias (sob essa denominação há grande quantidade de espécies pertencentes às Pteridófitas). 
DOI: $10.12957 / \mathrm{e}-\mathrm{mosaicos} .2021 .46188$

Figura 5 - Classificação das espécies arbóreas citadas pelos alunos pré e pós visita (\%).

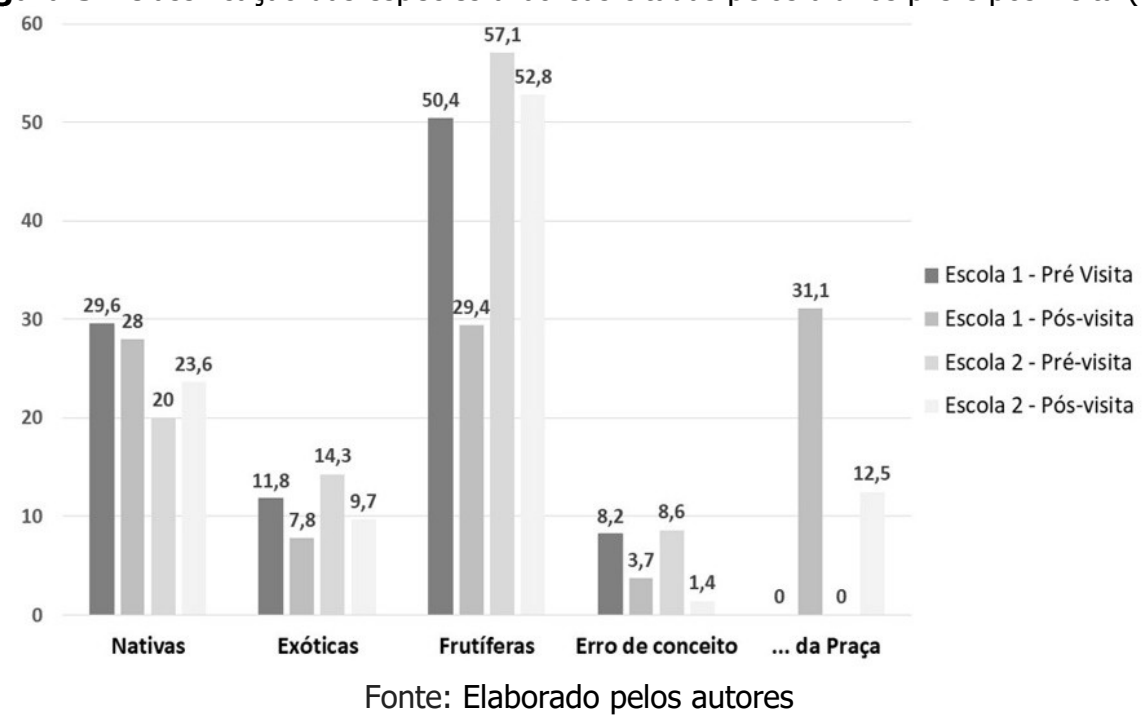

No entanto, no questionário respondido após a visita, as árvores frutíferas continuaram sendo a opção com maior percentual na Escola 2, com 52,8\%, porém, na Escola 1, as espécies presentes na praça superaram as demais, com $31,1 \%$ das respostas.

Durante a visita, nas apresentações via $Q R$ Code, algumas características das árvores foram discutidas com os visitantes, tais como o conceito de plantas perenes e decíduas, tendo como exemplo os Ipês (Handroanthus heptaphyllus (Mart.) Mattos) e as Tipuanas ( Tipuana tipu (Benth.) Kuntze); o conceito de acúleos e espinhos, usando como exemplo a Paineira (Ceiba speciosa (St. Hill.) Ravenna); o conceito de frutos e pseudofrutos, sendo este exemplificado pelos pseudofrutos da Uva do Japão (Hoveniadulcis); a presença de plantas parasitas nos galhos dos Álamos (Populusnigra) e de epífitas nos galhos do Ipê de El Salvador (Tabebuia pentaphylla Hemsl.); e por último, algumas diferenças entre angiospermas e gimnospermas, pois, na praça, há somente um exemplar de gimnosperma - Cipreste Calvo ( Taxodium mucronatum Ten.). No questionário pós-visita, os resultados obtidos apontam que, para os alunos da Escola 1, as atividades foram mais eficientes com acertos acima de $70 \%$, com exceção do entendimento do conceito de pseudofrutos, com 52,2\%. Para os alunos da Escola 2, o conceito de plantas decíduas obteve o percentual de $66,7 \%$ e os resultados apontam que o conceito ou diferenças entre angiospermas e gimnospermas foram compreendidos por apenas 33,3\% dos alunos (Fig.6).

De acordo com Nichele,Schlemmer e Ramos (2015, p. 7) 
DOI: $10.12957 / \mathrm{e}-\mathrm{mosaicos} .2021 .46188$

Da crescente adoção de dispositivos móveis, como smartphones e tablets entre os estudantes e os professores, emerge o potencial desses dispositivos como meio de inovação dos processos de ensino e de aprendizagem, especialmente no que se relaciona à ação e à interação dos sujeitos, bem como a forma de produzir, acessar e compartilhar a informação no contexto da mobilidade.

Figura 6 - Acertos dos conceitos botânicos discutidos ao longo da visita e que foram perguntados pós visita (\%).

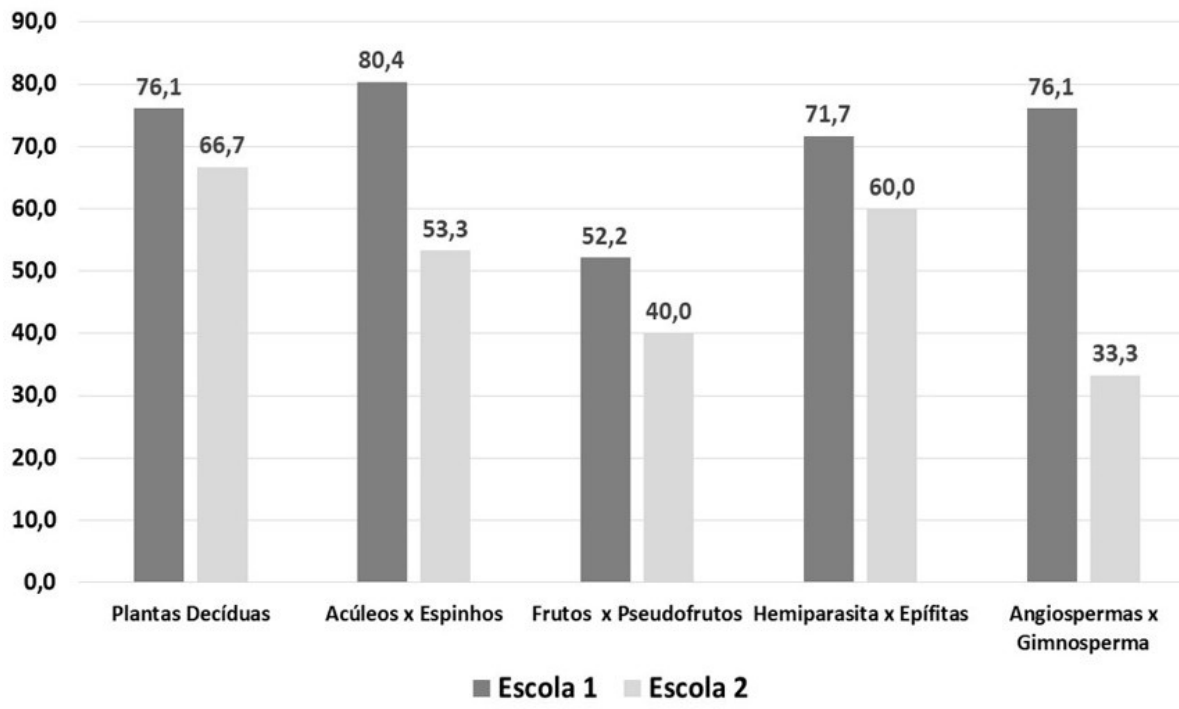

Fonte: Elaborado pelos autores

No entanto, quando perguntado aos alunos sobre os aspectos positivos e negativos da atividade, não havia uma pergunta específica para o uso do $Q R$ Code, sendo que o uso da ferramenta foi apontado como ponto positivo por apenas $12,5 \%$ dos alunos da Escola 1 e 33,3\% da Escola 2. Conhecer as árvores ou as espécies da praça foi apontado como positivo por $32,5 \%$ dos alunos da Escola 1 e por apenas 13,3\% dos alunos da Escola 2. Essa inversão de valores, na qual a tecnologia é mais importante para um grupo do que para outro, talvez possa ser explicada pelo acesso a esta. Sendo que a tecnologia enquanto ferramenta despertou mais a atenção do grupo de alunos da escola pública, que talvez possua menor acesso.

O sinal da internet e as placas quebradas foram os aspectos negativos mais citados pelas duas escolas (Quad. 2). 
DOI: $10.12957 / \mathrm{e}-\mathrm{mosaicos} .2021 .46188$

Quadro 2. Aspectos Positivos e aspectos negativos apontados pelos alunos (quantidade de alunos).

\begin{tabular}{|l|l|}
\hline \multicolumn{2}{|c|}{ AVALIAÇÃO DAS ATIVIDADES } \\
\hline ASPECTOS POSITIVOS & ASPECTOS NEGATIVOS \\
\hline ESCOLA 1 & ESCOLA 1 \\
\hline $\begin{array}{l}\text { Conhecer as árvores (novas } \\
\text { espécies, suas diversidades, países } \\
\text { de origem, suas características) (13) }\end{array}$ & Sinal ruim da internet (6) \\
\hline Conhecer o QR Code (5) & Responderam que gostaram de tudo (6) \\
\hline Das explicações apresentadas (4) & Barulho que prejudicou a visita (5) \\
\hline ESCOLA 2 & ESCOLA 2 \\
\hline Conhecer o QR Code (5) & Gostei de tudo (6) \\
\hline Jogo de quebra-cabeça (2) & As placas quebradas (5) \\
\hline $\begin{array}{l}\text { Aprender sobre as árvores e o que } \\
\text { elas representam em nossas vidas } \\
\text { (2) }\end{array}$ & $\begin{array}{l}\text { Dificuldade para ouvir (1); não ter visto } \\
\text { todas as árvores (1); jogo de quebra-cabeça } \\
\text { (1); destruição das plantas (1) }\end{array}$ \\
\hline
\end{tabular}

Fonte: Elaborado pelos autores

\section{CONSIDERAÇõES FINAIS}

O projeto cumpriu com seus objetivos, já que apresentou às escolas das redes pública e particular da cidade uma proposta de ensino e de aprendizagem fora dos muros da escola, tendo como atrativo o uso de tecnologias da informação para o ensino de Botânica.

Entende-se que o uso do $Q R$ Code é mais uma ferramenta que poderá ser utilizada para o ensino de Ciências, em particular no ensino de Botânica, sem que perca o foco principal referente à temática, como um instrumento que pode aliar o conhecimento dos conteúdos e aproximar os alunos e os professores à atualidade. 
DOI: $10.12957 / \mathrm{e}-\mathrm{mosaicos} .2021 .46188$

\section{REFERÊNCIAS}

ARAÚJO, M. S.; MIGUEL, J. R. Herbário didático no ensino da botânica. In: Encontro de Pesquisa em Ensino de Ciências e Matemática: questões atuais, 1, 2013, Duque de Caxias. Anais... Duque de Caxias: Unigranrio, 2013. p. 58-60.

BACKES, P.; IRGANG, B. Árvores do Sul: guia de identificação \& interesse ecológico: as principais espécies nativas sul-brasileiras. Rio de Janeiro: Instituto Souza Cruz, 2002. 325 p.

BACKES, P.; IRGANG, B. Árvores cultivadas no Sul do Brasil: guia de identificação e interesse paisagístico das principais espécies exóticas. Porto Alegre: Paisagem do Sul, 2004. v. 1. 204 p.

BARDIN, L. Análise de conteúdo. São Paulo: Edições 70, 2011.

BRASIL. Ministério da Educação. Base Nacional Comum Curricular. Brasília: MEC/Consed/Undime, 2017. Disponível em: http://basenacionalcomum.mec.gov.br/abase/. Acesso em: 02 mar. 2018.

BRASIL. Ministério do Meio Ambiente. Curso de identificação botânica de espécies arbóreas da região amazônica. Brasília: MMA/CENAFLOR/Serviço Social Brasileiro, 2009.

BRASIL. Ministério da Educação. Secretaria de Articulação com os Sistemas de Ensino. Planejando a próxima década: conhecendo as 20 metas do plano nacional de educação. Brasilia: MEC/SASE, 2014.

CARVALHO, L. M. Os trabalhos de campo como procedimento didático. In: SÃO PAULO. Secretaria de Meio Ambiente. Coordenadoria de Educação Ambiental. Educação ambiental: a qualidade das águas. São Paulo: SMA/CEAM, 1998. p. 23-31.

CASTOLDI, R; POLINARSKI, C. A. A utilização de Recursos didático-pedagógicos na motivação da aprendizagem. In: Simpósio Nacional de Ensino de Ciência e Tecnologia, 1, 2009, Ponta Grossa. Anais... Ponta Grossa: UTFPR, 2009.

DINARDI, A. J. A Pedagogia Histórico-Crítica como prática pedagógica em Educação Ambiental com enfoque em resíduos sólidos urbanos. Dissertação de Mestrado, Faculdade de Ciências, Universidade Estadual Paulista "Júlio de Mesquita Filho", Bauru, 2005.

DINARDI, A. J.; FEIFFER, A. H. S.; FELIPPELLI, H. E. O uso de praças públicas como espaço não formal de educação. Revista Educação, Cultura e Sociedade, v. 8, n. 1, p. 311326, 2018. 
DOI: $10.12957 / \mathrm{e}-\mathrm{mosaicos} .2021 .46188$

FRANTZ, A.M.F.; BRUSTOLIN, J.G.; KRONHARDT, K.; RODRIGUES, M.S.; NUNCIO, A.P.; CUNHA, G.F. O uso do QR Code para o ensino de zoologia. In: Congresso Brasileiro de Zoologia, 31, 2016, Cuiabá. Anais. Cuiabá: Angélico Asenjo Editor, 2016. p. 626-626.

GUIMARÃES, M. I. S. O uso de Tecnologias de Informação para a construção de conhecimentos nos sistemas de aprendizagem no ensino médio do IFMG. Dissertação de Mestrado Profissional, Universidade FUMEC, Belo Horizonte, 2015.

KLIX. T. Torne suas aulas mais interativas com QR Codes. Revista Nova Escola, 07 mar. 2018. Disponível em: https://novaescola.org.br/conteudo/4733/blog-tecnologia-tornesuas-aulas-mais-nterativas-com-qr-codes. Acesso em: 02 mar. 2018.

KRASILCHIK, M. Prática de ensino de biologia. 4. ed. São Paulo: Edusp, 2008.

MOREIRA-CONEGLIAN, I. R.; DINIZ, R. E. S.; BICUDO, L. R. H. Educação ambiental em praça pública no município de Botucatu/SP. Revista Ciência em Extensão, v. 1, n. 1, p. 39$52,2004$.

NICHELE, A. G.; SCHLEMMER, E.; RAMOS, A. F. QR Codes na educação em química. Revista Renote: Novas Tecnologias na Educação, v. 13, n. 2, p. 1-9, 2015.

NICOLA, J. A; PANIZ, C. M. A importância da utilização de diferentes recursos didáticos no ensino de ciências e biologia. InFor - Inovação e Formação: Revista do Núcleo de Educação a Distância da Unesp, v. 2, n. 1, p.355-381, 2016.

OLIVEIRA, T. T. Uso de TICS no ensino de biologia: um olhar docente. Monografia de Especialização, Pólo UAB do Município de Umuarama, Universidade Tecnológica Federal do Paraná, Medianeira, 2013.

PESSANO, E.F.C.; PESSANO, C. A. ; FOLMER, V ; PUNTEL, R. O rio Uruguai como tema para a educação ambiental no ensino fundamental. Revista Contexto \& Educação, v. 30, n. 96, p. 29-63, 2015.

SANTANA, D. S. M. Aplicação de recursos didáticos no ensino de ciências em uma escola pública de São Bentinho-PB. Trabalho de Conclusão de Curso, Universidade Federal da Paraíba, João Pessoa, 2015.

SERAFIM, M. C. A falácia da dicotomia teoria-prática. Revista Espaço Acadêmico, v. 1, n. 7, p. 1-2, dez. 2001. 
DOI: $10.12957 / \mathrm{e}-$ mosaicos.2021.46188

SILVA, T. B.; BEZERRA, S. M. C. B. O uso do QR CODE no ensino de matemática na formação inicial. In: Simpósio Linguagens e Identidades da/na Amazônia Sul Ocidental, 10, 2016, Rio Branco. Anais... Rio Branco: Universidade Federal do Acre, 2016.

SOBRAL, M.; JARENKOW, J.A.; BRACK, P.; IRGANG, B.; LAROCCA, J.; RODRIGUES, R.S. Flora Arbórea e Arborescente do Rio Grande do Sul, Brasil. São Carlos, RIMA, Novo Ambiente. 2006.350p.

Recebido em 27 de março de 2020

Aceito em 27 de setembro de 2020 de Aplicação Fernando Rodrigues da Silveira (CAp-UERJ) está disponibilizada sob uma Licença Creative Commons - Atribuição - NãoComercial 4.0 Internacional.

Os direitos autorais de todos os trabalhos publicados na revista pertencem ao(s) seu(s) autor(es) e coautor(es), com o direito de primeira publicação cedido à e-Mosaicos.

Os artigos publicados são de acesso público, de uso gratuito, com atribuição de autoria obrigatória, para aplicações de finalidade educacional e não-comercial, de acordo com o modelo de licenciamento Creative Commons adotado pela revista. 